\title{
Debye-Waller Factor Low Temperature Anomalies in $\mathrm{BaPb}_{1-x} \mathrm{Bi}_{x} \mathrm{O}_{3}$
}

\author{
A.P. Menushenkov, S. Benazeth*, J. Purans**, A.Yu. Ignatov and K.V. Klementev \\ Moscow Engineering Physics Institute, Kashirskoe shosse 31, 115409 Moscow, Russia \\ * Laboratoire pour l'Utilisation du Rayonnement Électromagnétique, 91405 Orsay, France \\ ** Institute of Solid State Physics, Latvia University, 226063 Riga, Latvia
}

\begin{abstract}
Temperature dependent $x$-ray absorption investigations have been made on the $\mathrm{Bi}_{2}$ edge in $\mathrm{BaPb}_{1-\mathrm{x}} \mathrm{Bi}_{\mathrm{x}} \mathrm{O}_{3}$ with $\mathrm{x}=0.0$, $0.75,1.0$. Essentially abnormal behaviour of the Debye-Waller factor $\sigma^{2}$ of $\mathrm{Bi}-\mathrm{O}$ bonds was observed at low temperatures for $\mathrm{BaBiO}_{3}$ and $\mathrm{BaPb}_{0.25} \mathrm{Bi}_{0.75} \mathrm{O}_{3}$ in contrast to Einstein model. It was found that the Debye-Waller factors of both $\mathrm{Bi}-\mathrm{O}$ bonds increase with temperature decreasing from $\sim 90 \mathrm{~K}$ along with abnormal increasing of $\mathrm{Bi}-\mathrm{O}$ and $\mathrm{Bi}-\mathrm{Ba}$ distances. At the same time $\mathrm{Pb}-\mathrm{O}, \mathrm{Pb}-$ $\mathrm{Ba}$ bonds of $\mathrm{BaPbO}_{3}$ show normal behaviour with temperature. The nature of the anomalies is discussed in the frame of the dynamic fluctuation of the oxygen octahedra rotation mode that may give a new look to understanding of HTSC phenomenon in $\mathrm{BaPb}_{1-\mathrm{x}} \mathrm{Bi}_{\mathrm{x}} \mathrm{O}_{3}$ and $\mathrm{Ba}_{1-\mathrm{x}} \mathrm{K}_{\mathrm{x}} \mathrm{BiO}_{3}$
\end{abstract}

\section{INTRODUCTION}

Despite the superconductivity in the $\mathrm{BaPb}_{1-\mathrm{x}} \mathrm{Bi}_{\mathrm{x}} \mathrm{O}_{3}(\mathrm{BPB})$ was discovered considerably earlier [1] than in cuprates [2], there is no generally accepted description of the mechanism of superconductivity in these alloys so far. Moreover, it is not clear if the paring mechanism is the same in the similar compounds of $\mathrm{BPB}$ and $\mathrm{Ba}_{1-\mathrm{x}} \mathrm{K}_{\mathrm{x}} \mathrm{BiO}_{3}(\mathrm{BKB})$ [3].

There is considerable controversy concerning phase diagram of superconducting BPB alloys $(0<x<0.35)$ and for both $B P B$ end members; $\mathrm{BaBiO}_{3}$ and $\mathrm{BaPbO}_{3}$ (see, e.g. [4]). In the diffraction studies [5,6] an essential anisotropy in the thermal vibration of oxygen atoms (oblate along the Bi-O-Bi bonds) for both BPB and BKB systems was observed. Heald et al. [7] (XAS study) found some peculiarities of the BKB local structure at low temperatures: two different temperature dependencies of the DebyeWaller (DW) factor $\sigma^{2}$ were obtained for two $\mathrm{Bi}-\mathrm{O}$ bonds in $\mathrm{BaBiO}_{3}$, for the superconducting compound $\left(\mathrm{Ba}_{0.6} \mathrm{~K}_{0.4} \mathrm{BiO}_{3}\right)$ the $\sigma^{2}$ temperature behaviour showed a significant deviation from the Einstein model. Besides, an abnormal increase of the both $\mathrm{Bi}-\mathrm{O}$ distances with the temperature decrease was observed in a pure and slightly potassium doped $\mathrm{BaBiO}_{3}[8]$.

All these uncertainties seem to arise from the complexity of the BPB and BKB structures due to two unequal Bi positions. Here we present an EXAFS- study of the local structure anomalies for the BPB compounds which are more pronounced at low temperatures and discuss their nature in the frame of perovskite structure peculiarities.

\section{EXPERIMENT AND EXAFS DATA REDUCTION}

The samples of $\mathrm{BaPb}_{1-\mathrm{x}} \mathrm{Bi}_{\mathrm{x}} \mathrm{O}_{3}$ with $\mathrm{x}=0,0.75$, and 1 were prepared by heating mixtures of oxides and carbonates $(\mathrm{BaCO}$, $\mathrm{Pb}_{3} \mathrm{O}_{4}$, and $\mathrm{Bi}_{2} \mathrm{O}_{3}$ ) in air at $800-1000^{\circ} \mathrm{C}$. The powder samples were three times annealed and then slowly cooled and ground. All the samples had a pure phase, which was examined by $x$-ray diffraction. For the EXAFS measurements the fine powder was uniformly deposited on polytetrafluoroethylene membrane. Their thickness was about 2 absorption lengths.

The x-ray absorption measurements were performed on D21 beam line of the DCI storage ring LURE (France) at the Bi and $\mathrm{Pb} \mathrm{L} \mathrm{L}_{3}$ edges using a $\mathrm{Si}(111)$ double-crystal monochromator. The storage ting was operated at $1.85 \mathrm{GeV}$ positron beam energy and $300 \mathrm{~mA}$ maximum current. The energy resolution was $\sim 3 \mathrm{eV}$ at $13 \mathrm{keV}$. The low temperature measurements were carried out with a liquid helium circulation cryostat. The temperature was regulated by a helium flow and measured with a carbon probe with the accuracy about $1 \mathrm{~K}$.

The XAFS function $\chi(k)$ was filtered by Fourier technique. Near neighbour distance $R$, the DW factor $\sigma^{2}$, and the number of the neighbours $N$ related to the sphere obtained were determined by fitting as:

$\chi(k)=N F(k) \sin [2 k R+\varphi(k)] \exp \left(-2 k^{2} \sigma^{2}\right) / k R^{2}$

The phase shift $\varphi(k)$ and the scattering amplitude $F(k)$ were calculated using the FEFF- 5 code.

The closeness of $\mathrm{L}_{3} \mathrm{~Pb}(13.035 \mathrm{keV})$ and $\mathrm{Bi}(14.418 \mathrm{keV})$ edges complicates the quantitative analysis of the mixed compounds $(x \neq 0,1)$. The $P b$ background presents noticeably above the $B i L_{3}$ edge and should be subtracted. A possible way of solving this problem is to construct a model using the data between the $\mathrm{Pb}$ and $\mathrm{Bi} \mathrm{L}_{3}$ edges [9] and to prolong it over the $\mathrm{Bi} \mathrm{L}_{3}$ edge. Here we used the subtraction of the $\chi(k)$ of the $\mathrm{BaPbO}_{3}$ experimental spectra $\left(\mathrm{Pb} \mathrm{L}_{3}\right.$ edge) taken at the same temperature. In this case the subtracted spectrum contains information about all the coordination shells (in contrary to the subtraction of the model $\chi(k)$ that contains 2 or 3 shells only). At the same time there is some difference between the local environment of $\mathrm{Pb}$ in the mixed compounds and in the $\mathrm{BaPbO}_{3}$ and for the $\mathrm{x}=0.75$ compound this difference is not negligible. Nevertheless, the $\mathrm{Pb}$ 
absorptance is three times as small as the $\mathrm{Bi}$ one and some shortage of accuracy in such a small $\mathrm{Pb}$ background is not so important.

\section{GENERAL RESULTS}

For the $\mathrm{BaPbO}_{3}(\mathrm{x}=0)$ and $\mathrm{BaBiO}_{3}(\mathrm{x}=1)$, the EXAFS data were obtained by the Fourier transform (FT) over the range 3-14 $\AA^{-1}$ in $k$-space. The back Fourier transform was done using square windows $1.0-2.1 \AA$ for $\mathrm{Pb}-\mathrm{O}$ and $\mathrm{Bi}-\mathrm{O}$ shells and $2.5-4.0 \AA$ for the $\mathrm{Pb}(\mathrm{Bi})-\mathrm{Ba}$ shell. For $\mathrm{x}=0.75$ compound, the $k$-range of FT's at the $\mathrm{Pb} \mathrm{L}_{3}$ edge is limited by $9.6 \AA^{-1}$, where the $\mathrm{Bi} \mathrm{L}_{3}$ edge begins. This limitation broadens the peaks of the FT and, hence, produces some uncertainties in the amplitudes and the DW factors. Data from the $\mathrm{Bi} \mathrm{L}_{3}$ fine structure were extracted after the subtracting the oscillating background from the $\mathrm{Pb} \mathrm{L}_{3}$ edge. For this procedure we used the $\mathrm{Pb} \mathrm{L}_{3}$ XAFS from $\mathrm{BaPbO}_{3}$ measured at the same temperatures. The $\mathrm{Pb} \mathrm{L}_{3} \mathrm{XAFS}$ was transformed back to the energy scale $\left(E=E_{0} \tau \hbar^{2} k^{2} / 2 m_{\mathrm{e}}\right)$ and renormalised to the step height at the $\mathrm{Pb} \mathrm{L}_{3}$ edge: $\mu(E)=\chi(E) \mu_{0}(E)+\mu_{0}(E)$. This spectrum reproduces completely the area between the $\mathrm{Pb}$ and $\mathrm{Bi} \mathrm{L}_{3}$ edges. After the subtraction we obtain the EXAFS spectrum that is relatively free of the $\mathrm{Pb} \mathrm{L}_{3}$ edge contribution. Then, using the forward and back FT, we have got partial spheres of the oxygen and barium for all the compounds. To get numerical results we performed non-linear least-square fit in the $k$ space. The $\mathrm{Pb}(\mathrm{Bi})-\mathrm{O}$ and $\mathrm{Pb}(\mathrm{Bi})$ - $\mathrm{Ba}$ distances are summarised in Table $\mathrm{I}$ with an error of $\sim 0.01 \AA$.

For the $\mathrm{Pb}$ first neighbour environment we have found that there is only one $\mathrm{Pb}-\mathrm{O}$ distance for both $\mathrm{x}=0$ and $\mathrm{x}=0.75$ compounds. The thermal expansion caused an ordinary increasing the $\mathrm{Pb}-\mathrm{O}$ and $\mathrm{Pb}-\mathrm{Ba}$ distances as well as an increasing the DW factor of $\mathrm{Pb}-\mathrm{O}$ bond (see Table $\mathrm{I}$ ).

For undoped $\mathrm{BaBiO}_{3}$ (see Table I) we have determined two Bi-O distances separated by $0.15 \AA$ at $300 \mathrm{~K}$ and by $0.18 \AA$ at $7 \mathrm{~K}$. The difference between the two Bi-O bond lengths agrees with other XAFS studies and data of neutron diffraction [7-10].

Table 1. The results of EXAFS analysis $\left(r, \AA ; \sigma^{2}, 10^{-3} \AA^{2}\right)$.

$\mathrm{BaPbO}_{3}$

\begin{tabular}{|l|ll|ll|}
\hline $\mathrm{T}, \mathrm{K}$ & $\mathrm{r}(\mathrm{Pb}-\mathrm{O})$ & $\sigma^{2}(\mathrm{~Pb}-\mathrm{O})$ & $\mathrm{r}(\mathrm{Pb}-\mathrm{Ba})$ & $\sigma^{2}(\mathrm{~Pb}-\mathrm{Ba})$ \\
\hline 7 & 2.15 & 0.76 & 3.76 & 3.1 \\
30 & 2.16 & 0.93 & 3.76 & 3.5 \\
80 & 2.16 & 1.04 & 3.76 & 3.9 \\
90 & 2.17 & 1.20 & 3.76 & 3.9 \\
100 & 2.17 & 1.42 & 3.77 & 4.0 \\
250 & 2.18 & 1.44 & 3.77 & 8.1 \\
\hline
\end{tabular}

$\mathrm{BaBiO}_{3}$

\begin{tabular}{|l|llll|ll|}
\hline $\mathrm{T}, \mathrm{K}$ & $\mathrm{r}(\mathrm{Bi}-\mathrm{O})_{1 / 2}$ & $\sigma^{2}(\mathrm{Bi}-\mathrm{O})_{1 / 2}$ & $\Delta \mathrm{r}$ & $\langle\mathrm{r}>$ & $\mathrm{r}(\mathrm{Bi}-\mathrm{Ba})$ & $\sigma^{2}(\mathrm{Bi}-\mathrm{Ba})$ \\
\hline 7 & $2.15,2.34$ & $2.3,4.8$ & 0.19 & 2.24 & 3.83 & 2.9 \\
30 & $2.14,2.32$ & $2.0,4.3$ & 0.18 & 2.23 & 3.82 & 3.1 \\
55 & $2.13,2.31$ & $0.7,2.0$ & 0.18 & 2.22 & 3.81 & 3.7 \\
90 & $2.14,2.30$ & $0.6,2.4$ & 0.16 & 2.22 & 3.81 & 3.9 \\
250 & $2.14,2.29$ & $3.0,6.0$ & 0.15 & 2.22 & 3.80 & 7.0 \\
\hline
\end{tabular}

$\mathrm{BaPb}_{0.25} \mathrm{Bi}_{0.75} \mathrm{O}_{3}$

\begin{tabular}{|l|llll|ll|}
\hline $\mathrm{T}, \mathrm{K}$ & $\mathrm{r}(\mathrm{Bi}-\mathrm{O})_{\mathrm{I} / 2}$, & $\Delta \mathrm{r}$ & $\langle\mathrm{r}\rangle$ & $\mathrm{r}(\mathrm{Pb}-\mathrm{O})$ & $\mathrm{r}(\mathrm{Bi}-\mathrm{Ba})$ & $\mathrm{r}(\mathrm{Pb}-\mathrm{Ba})$ \\
\hline 7 & $2.14,2.29$ & 0.15 & 2.21 & 2.21 & 3.81 & 3.80 \\
30 & $2.13,2.28$ & 0.15 & 2.21 & 2.19 & 3.81 & 3.79 \\
$\mathbf{5 5}$ & $2.12,2.26$ & 0.14 & 2.19 & 2.19 & 3.80 & 3.78 \\
250 & $2.12,2.25$ & 0.13 & 2.18 & 2.18 & 3.79 & 3.77 \\
\hline
\end{tabular}

We observed an abnormal temperature dependence of the $\mathrm{Bi}-\mathrm{O}$ bond $\mathrm{DW}$ factors for compounds with $\mathrm{x}=1.0,0.75$ at temperature range 7-90 K. As can be seen from Fig. 1 and Table. I, the DW factors of both Bi-O bonds increase with the temperature decreasing. From the Einstein model's point of view, which should fit well the temperature dependence of harmonic systems, this tendency is absolutely abnormal.

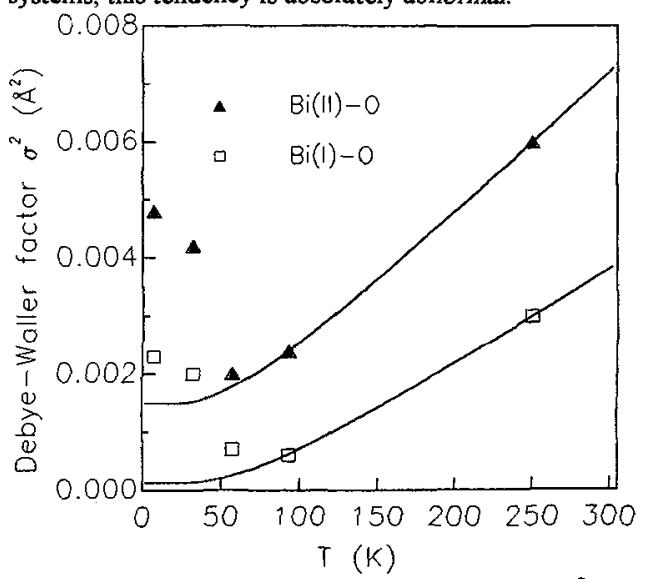

Figure 1. Temperatume dependences of the DW factors $\sigma^{2}$ for the oxygen subshells in $\mathrm{BaBiO}_{3}$ with the longer bond leagth $(\Delta)$ and with the shorter one (D). The solid lines are the Einstein madel fits.

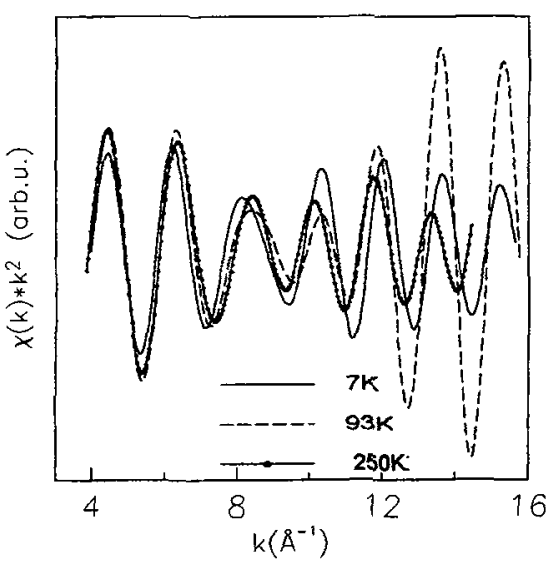

Figure 2. First (oxygen) shell at $\mathrm{Bi} \mathrm{L}_{3}$ edge for $\mathrm{BaBiO}_{3}$ at different temperatures: $7,90,250 \mathrm{~K}$. 
To illustrate the reality of our results we present in Fig. 2 the isolated first shell of $k^{2} * \chi(k)$ for $\mathrm{BaBiO}_{3}$ at three temperatures: $7 \mathrm{~K}, 93 \mathrm{~K}$ and $250 \mathrm{~K}$. One can see that the beating at $93 \mathrm{~K}$ is stronger not only than at $250 \mathrm{~K}$ but also than at $7 \mathrm{~K}$, which indicates that at $93 \mathrm{~K}$ the contributions of the both $\mathrm{Bi}-\mathrm{O}$ shells are almost equal so that their interference in the EXAFS spectra has a maximum effect near this temperature. In the case of the ordinary $\sigma^{2}(\mathrm{~T})$ dependence for the both $\mathrm{Bi}-\mathrm{O}$ bonds the strongest beat would be observed at the lowest temperature.

The anomalies in behaviour of DW factors are accompanied by an abnormal increasing of $\mathrm{Bi}-\mathrm{O}$, Bi-Ba distances with temperature decreasing from $90 \mathrm{~K}$ to $7 \mathrm{~K}$ for both $\mathrm{x}=1$ and $\mathrm{x}=0.75$ samples. It is in agreement with results of Salem-Sugui,Jr $e t$ $a l .[8]$ and with the negative linear thermal coefficient of expansion found by Anshukova et al. [11].

With the temperature decreasing, the difference between two Bi-O bond lengths increases from $0.15 \AA(250 \mathrm{~K})$ to $0.18 \AA$ (7 K) due to the increase of the longer Bi-O bond length $(2.29 \AA(250 \mathrm{~K})-2.34 \AA(7 \mathrm{~K}))$. At the same time the shorter Bi-O bond length does not practically change (see Table I).

\section{DISCUSSION}

It is worth to notice, that the DW factors increasing with a temperature fall is very unusual phenomena. Previously the same behaviour was observed in the mixed valence $\mathrm{Sm}_{0.7} \mathrm{Y}_{0.3} \mathrm{~S}$ and was connected with softening of optics phonons [12]. We suppose that the anomalies in $\mathrm{BaBiO}_{3}$ arise from the asymmetry of the dynamic fluctuation of the oxygen octahedra rotation (tilting) mode. Tilting vibration displacements produce the additional fluctuation of $\mathrm{Bi}-\mathrm{O}$ lengths with rotation mode frequency. Thus, the values of the DW factor $\sigma^{2}$ of Bi-O bonds extracted from the EXAFS spectra should contain at least two parts: $\sigma_{b}^{2}$ and $\sigma_{r}^{2}$ from the breathing and rotation modes respectively. At high temperatures ( $T>90 \mathrm{~K}$ ) the value of $\sigma_{\mathrm{r}}^{2}$ is negligible in comparison with $\sigma_{b}^{2}$ and the temperature dependencies of the DW factor $\sigma^{2}$ are in the agreement with the Einstein model

With temperature decreasing, the static tilting angle grows $[4,7]$, which increases both the long Bi-O distance and the contribution from the tilting fluctuations into $\sigma^{2}$ value (see Tab. 1 and Fig. 1). Besides, it is known [13], that the fluctuation of the tilting displacement becomes remarkable on cooling. Thus, from our viewpoint the anomalous behaviour of the DW- factors for monoclinic distorted $\mathrm{BaBiO}_{3}$ arise from the rotation part $\sigma_{x}^{2}$ in the total $\sigma^{2}(\mathrm{~T})$ temperature dependence (see Fig.1). Apparently, owing to the essential difference in the $\mathrm{Bi}-\mathrm{O}$ bond lengths, the fluctuation asymmetry of the tilting mode is considerable and leads to a negative thermal expansion coefficient [11]. It was observed as the Bi-Ba bond length growth for both the $\mathrm{BaBiO}_{3}$ and $\mathrm{BaPb}_{0.25} \mathrm{Bi}_{0.75} \mathrm{O}_{3}$ compounds in our experiments (see Table I)

In contrast to monoclinic distorted $\mathrm{BaBiO}_{3}$, the other $\mathrm{BPB}$ end member $\mathrm{BaPbO}_{3}$ has a weak lattice distortion. All $\mathrm{Pb}-\mathrm{O}$ bonds have the same strength. The oxygen octahedra around the $\mathrm{Pb}$ atoms are equivalent. That is why the $\mathrm{Pb}-\mathrm{O}$ bond length and its $\mathrm{DW}$ factor show an ordinary growth with temperature, unlike those in $\mathrm{BaBiO}_{3}$ and $\mathrm{BaPb}_{0.25} \mathrm{Bi}_{0.75} \mathrm{O}_{3}$.

In the superconducting $\mathrm{BPB}$ compound with $\mathrm{x}=0.25$ our previous results also showed an ordinary increase of $\mathrm{Bi}-\mathrm{O}$ and $\mathrm{Bi}$ $\mathrm{Ba}$ bond lengths with temperature. Probably it is connected with a less distorted structure compared with $\mathrm{BaBiO}_{3}$ due to a small bismuth content [4].

A possible connection of the rotation mode fluctuation with superconductivity in BKB, BPB systems was noticed in a number of works $[13,14]$. The rotation type vibration mode of oxygen octahedra plays the main role in the anharmonic model for high- $\mathrm{T}_{\mathrm{c}}$ superconductors by Plakida et al. [14]. That is why it is necessary to carry out more accurate investigations of local structure in the superconducting phases $\mathrm{BaPb}_{1-\mathrm{x}} \mathrm{Bi}_{\mathrm{x}} \mathrm{O}_{3}(0<\mathrm{x}<0.35)$ and $\mathrm{Ba}_{1-\mathrm{x}} \mathrm{K}_{\mathrm{x}} \mathrm{BiO}_{3}(0.37<\mathrm{x}<0.5)$ at low temperature. Such a study is under way (see preliminary results in Ref.[15]) and will be published later.

\section{Acknowledgements}

The authors (excluding S.B.) are very grateful to Prof. H.Dexpert and the LURE program committee for the supporting of our projects PS-207-94, PS-056-95 at LURE. This work was supported by grant MG-2300 of International Science Foundation and grant 96-02-19099a of Russian Foundation for Basic Research.

\section{References}

[1] A.W.Sleight, J.L.Gillson, P.E.Bierstedt, Solid State Commun. 17 (1975) 27 ;

[2] J.G.Bednorz, K.A.Muller, Z.Phys B 64 (1986) 189;

[3] M.Shirai, N.Suzuki, and K.Motizuki, J. Phys. Condens. Matter, 2 (1990) 3553 ;

[4] D.T.Marx, P.G.Radaelli, J.D.Jorgensen, R.L.Hitterman, D.G.Hinks, Shiyou Pei, B.Dabrowski, Phys.Rev. B 46 (1992) 1144;

[5] D.E.Cox and A.W.Sleight, Acta Crystallogr. B 35 (1979) 1;

[6] J.P.Wignacourt, J.S.Swinnea, H.Steinfink, J.B.Goodenough Appl.Phys.Lett. 53 (1988) 1753;

[7] S.M.Heald, D.DiMarzio, M.Croft, M.S.Hegde, S.Li, M.Freenblatt, Phys.Rev. B 40 (1989) 8828;

[8] S.Salem-Sugui,Jr., E.E.Alp, S.M.Mini, M.Ramanathan, J.C.Campuzano, G.Jennings, M.Faiz, S.Pei, B.Dabrovski, Y.Zheng, D.R.Richards,

D.G.Hinks, Phys.Rev. B 43 (1991) 5511;

[9] J.B.Boyce, F.G.Bridges, T.Claeson, T.H.Geballe, G.G.Li, and A.W.Sleight, Phys. Rev. B 44 (1991) 6961;

[10] G.Thornton, A.J.Jacobson, Acta Crystallogr. B 34 (1978) 351;

[11] N.V.Anshukova, A.I.Golovashkin, Yu.V.Bugoslavskii, L.I.lvanova, A.P.Rusakov, I.B.Krinetskii , J. of Supercond. 7 (1994) 427;

[12] P.D.Dernier, W.Weber, and L.D.Longinotti, Phys. Rev. B 14 (1976) 3635.

[13] Y.Koyama, M.Ishimaru, Phys. Rev. B 45 (1992) 9966; Y.Koyama, S.-I. Nakamura, Y.Inoue, Ibid 46 (1992) 9186

[14] N.M.Plakida, V.L.Aksenov, S.L.Drechsler, Proc. of the Adriatico Res. Conf on HTSC, Trieste, 5-8 July 1987, Singapore: World Scientific (1987) 1071.

[15] A.P.Menushenkov, S.Benazeth, J.Purans, A.Yu.Ignatov, K.V.Klementev, Preprint MEPhI 007-95, Moscow (1995) 